Sciences and Public Health Research, Leeds University, and Division of Dementia Studies, Bradford University.

Green, H., McGinnity, A., Meltzer, H., et al (2005) Mental Health of Children and Young People in Great Britain, 2004. Office for National Statistics.

HM Government (2011a) No Health Without Mental Health: A Cross Government Mental Health Outcomes Strategy for People of All Ages. Department of Health.

HM Government (2011b) No Health Without Mental Health: Delivering Better Mental Health Outcomes for People of All Ages. Department of Health.

Kessler, R. \& Wang, P. (2007) The descriptive epidemiology of commonly occurring mental disorders in the United States. Annual Review of Public Health, 29, 115-129.

Kim-Cohen, J., Caspi, A., Moffitt, T., et al (2003) Prior juvenile diagnoses in adults with mental disorder. Archives of General Psychiatry, 60, 709-717.

Knapp, M. \& Prince, M. (2007) Dementia UK: A Report into the Prevalence and Cost of Dementia. Alzheimer's Society.

McManus, S., Meltzer, H., Brugha, T., et al (2009) Adult Psychiatric Morbidity in England, 2007: Results of a Household Survey. NHS Information Centre for Health and Social Care.

Milne, A., Hatzidimitriadou, E., Chryssatholoplou, C., et al (2001) Caring in Later Life: Reviewing the Role of Older Carers. Help the Aged.
National Mental Health Development Unit (2009) National Suicide Prevention Strategy for England: Annual Report on Progress 2008. NMHDU.

O'Hara, M. W. \& Swain, A. M. (1996) Rates and risk of postpartum depression - a meta analysis. International Review of Psychiatry, 8, 37-54

Royal College of Psychiatrists (2010a) Looking Ahead: Future Development of UK Mental Health Services: Recommendations from a Royal College of Psychiatrists' Enquiry. Occasional Paper OP75. Royal College of Psychiatrists.

Royal College of Psychiatrists (2010b) No Health Without Public Mental Health: The Case for Action. Position Statement PS4. Royal College of Psychiatrists.

Singleton, N., Bumpstead, R., O'Brien, M., et al (2001) Psychiatric Morbidity Among Adults Living in Private Households, 2000. TSO.

Van Os, J., Linscott, R. J., Myin-Germeys, P., et al (2009) A systematic review and meta analysis of the psychosis continuum: evidence for a psychosis-proneness-persistence impairment model of psychotic disorder. Psychological Medicine, 39, 179-195.

World Health Organization (2004) Projections of Mortality and Global Burden of Disease 2004-2030. WHO.

World Health Organization (2008) Global Burden of Disease Report. WHO. Available at http://www.who.int/healthinfo/global burden disease/estimates_country/en/index.html (last accessed March 2011).

\title{
Psychiatry in paradise - the Solomon Islands
}

\section{Ashok N. Singh ${ }^{1}$ MD and Paul Orotaloa ${ }^{2}$ MD}

${ }^{1}$ Consultant Psychiatrist, Department of Psychiatry, Pilgrim Hospital, Boston, Linconshire, UK, email Ashok.Singh@LPFT.nhs.uk; ${ }^{2}$ Consultant Psychiatrist, Mental Health Unit, National Referral Hospital, Honiara, Solomon Islands

\begin{abstract}
- he Solomon Islands is situated in the South Pacific Ocean and is a low-income country. It comprises nearly 1000 islands with a total land area of $304000 \mathrm{~km}^{2}$ spread over a sea area of about $1500000 \mathrm{~km}^{2}$, making communications, travel and service delivery difficult and creating inequities in access. The population of the Solomon Islands was estimated to be just over 580000 in 2008, and is young, with $42 \%$ aged under 15 years (Solomon Islands Ministry of Health, 2006). The majority of the people are Melanesian (93\%) and $98 \%$ of the population belong to a Christian church. The population is, though, extremely diverse, with 91 indigenous languages and dialects being spoken, in addition to the Solomon Islands pijin (the most common language) and English (the official national language). Over $83 \%$ of the population live in rural areas, where subsistence agriculture, fishing and food gathering are the main sources of income. There is no substantial tourist industry. The gross domestic product (GDP) is US $\$ 1.5$ billion and annual per capita income is approximately US\$2800 (International Monetary Fund, 2009). Total expenditure on health represented $5.6 \%$ of GDP but only $1 \%$ of the total health budget is allocated to mental health (World Health Organization, 2005).
\end{abstract}

\section{Mental health policy and legislation}

Mental health has been attracting increasing attention in the Solomon Islands, with growing support for the adoption of a broad national mental health policy. Following agreement between the Ministry of Health and medical services, and the World Health Organization, a short-term consultant was mobilised from October 2008 to January 2009 to assist with the development of this policy. As part of the intensive consultation process, over 120 individuals were interviewed, including senior national and provincial staff of the Ministry of Health, non-governmental organisations, church leaders and relatives and carers for people with mental disorders. The feedback from a workshop and the consultation process was then incorporated into the national mental health policy.

\section{Mental health legislation}

The Mental Treatment Act 1970 consolidated the law relating to people of unsound mind and makes better provision for the care of persons suffering from mental disorders 
and for their custody, as well as governing the management and control of mental hospitals. There is now an attempt to include community and primary care facilities within the remit of the Act. The Act was amended in 1995 by two external consultants and attempts are now being made for its revision and passage through Parliament. The country's sole consultant psychiatrist (the second author) is responsible for the assessment of persons suffering from mental disorder under the Act.

\section{Mental health services}

Formal mental health services in the Solomon Islands date back to 1950, when an asylum was established in Honiara, the capital. It was principally a place for custody of anyone considered a danger to society or unable to care for themselves. In 1977, the government built a new 15-bed mental hospital on the grounds of Kilu'ufi Hospital in Auki, Malaita Province. In 1984, 12 new beds were added to accommodate female patients. Like its predecessor, the facility lacked qualified mental health staff and adequate resources.

The current mental health service has both national and provincial arms and has been built up around a small core of trained psychiatric nurses and one psychiatrist.

\section{The national arm}

The national arm includes the 20-bed National Psychiatric Unit in Auki and a 4-bed acute care unit at the National Referral Hospital in Honiara. Both facilities also provide outpatient services, but there is little community mental health activity other than general community awareness, although it is acknowledged that families need to be informed and supported if they are to provide continuing care and rehabilitation for patients after discharge.

Recently, a fully functioning community mental health and rehabilitation team was established with the help of the first author, a volunteer under the auspices of the World Health Organization and the Royal College of Psychiatrists (Singh, 2010). The main role of the volunteer was to improve the clinical skills of the local psychiatrist and senior nurses in terms of diagnosis, prescribing, psychosocial rehabilitation and psychoeducation with patients and families. Further aims were:

O to improve their management skills by holding and chairing regular meetings

o to develop the World Health Organization's model for community mental health services

o to establish individual care plans

$O$ to reduce relapse and readmission rates

o to improve mental health services to local prisons.

The volunteer was able to understand the local language most of the time and only on a few occasions did nursing staff have to be used as interpreters.

\section{The provincial arm}

The provincial arm is represented by identified mental health nurses (psychiatric coordinators) in six of the country's nine provinces: Choiseul, Guadalcanal, Ysabel, Makira, Temotu and Western. Acute treatment of severe mental disorder is not available at the primary care level; however, there is a basic continuum of service from acute care at the out-patient clinics to outreach services. The relapse and readmission rates are high, for various reasons, such as non-adherence to medication, intolerable side-effects and lack of aftercare in the community.

\section{Pharmacological interventions}

A national therapeutic drug policy/essential list of drugs operates. Only first-generation antipsychotics are available; fluphenazine decanoate depot injection is commonly used. The tricyclic antidepressants are available and sodium valproate is used as a mood stabiliser. The nurses give depot injections to patients in rural areas. All medications are provided free of charge to every patient. A discussion is ongoing over whether to include newer drugs on the essential list of drugs.

\section{Other service providers}

A discussion is ongoing over ways in which community resources could link with mental health services. Two important resources supplement the formal services: the churches and traditional healers.

\section{Churches}

The churches deliver a range of welfare services and psychosocial interventions to women, youths and families, including counselling and community development. Although the churches do link with specialist mental health services, these links are generally poor. The churches have a number of roles and church leaders are also role models. The churches run a trauma support programme that offers assistance to individuals, families and communities suffering from stress and trauma. This programme was further developed following a tsunami in 2007. The churches also try to engage young people, and keep them busy (through youth groups, sports and community programmes such as visiting old people) and away from trouble and antisocial activities such as substance misuse. None of the churches (or indeed other non-government organisations) focuses on providing core mental health services.

\section{Traditional healers}

Traditional healing practices vary across the country. They include song and dance, as well as the provision of food and medicine. In many places, such practices are the principal means of mental healthcare, being regarded as essential for cultural and spiritual well-being, while mental health services are the last resort.

\section{Training}

There are few personnel with mental health qualifications within the governmental mental health services. This has come about through limited opportunities for employment and an absence of a specialist tertiary course in the mental health field in the Solomon Islands. Since 1995, 11 psychiatric nurses and one psychiatrist (the current consultant psychiatrist) have been sent overseas for training. Another doctor is currently undergoing postgraduate training in psychiatry in Papua New Guinea. There are no psychiatric subspecialties in the country, so the sole psychiatrist looks after all patients. 


\section{Workforce}

As indicated above, there is an acute shortage of trained psychiatrists (with just one consultant) and mental health nurses. There are no medical schools in the Solomon Islands and there is no local postgraduate training in psychiatric nursing. Students are sent overseas, mostly to Cuba, to do their medical training and most of the nurses are sent to either Papua New Guinea or Fiji. Recently, the sole clinical psychologist resigned and the post was still vacant at the time of writing. The total number of posts in the mental health services is 55; there are seven vacancies at various grades. There is no central record of the number of health workers who have been trained, or when, to guide future education and training in mental health for primary care workers.

\section{Prevalence of mental disorder}

Epidemiological data on the prevalence and distribution of mental disorder, alcohol and drug use, and suicide and selfharm are lacking in the Solomon Islands. However, according to the 2006 national disability survey of the 14403 people with disabilities, $5.3 \%$ had a general intellectual disability, $3.5 \%$ had dementia, $2.8 \%$ had a psychiatric disorder and $3.9 \%$ had epilepsy.

Self-harm is a new but growing problem (Finau \& Losalo, 1985). In 2004 intentional self-poisoning was one of the ten leading causes of death recorded at the National Referral Hospital, Honiara. A review of the accident and emergency department's records from February to October 2008 revealed 77 recorded cases of self-harm and one suicide. From January 2009 to December 2009 there were 142 psychiatric consultations (see Table 1).

There are no culture-bound disorders specific to the Solomon Islands. More widely, in the South Pacific direct expression of dissatisfaction with an elder is constrained and is indirectly expressed in a person becoming musu (socially withdrawn); in extreme form the person may become clinically depressed and suicidal.

\section{Publications and research}

The Solomon Islands does not have a psychiatric journal and most research work is being done by donor organisations. This research has been on psychosocial aspects of mental problems, in particular in relation to youth, substance misuse, violence and HIV/AIDS. Australian researchers (Blignault et al, 2009) are looking into the community perception of mental health needs in the Solomon Islands.

\section{Conclusion}

In the Solomon Islands, mental health services have come a long way in recent years, but the harsh social economic
Table 1 Numbers of out-patient psychiatric consultations at the National Referral Hospital, January-December 2009

\begin{tabular}{lc} 
& $\begin{array}{l}\text { Number of } \\
\text { patients }\end{array}$ \\
Male (age range 10-76 years, mean 31 years) & 83 \\
Female (age range 13-80 years, mean 30 years) & 59 \\
Generalised anxiety disorder/panic/ & 45 \\
$\quad$ anxiety/somatoform disorder & \\
Stress/adjustment disorder & 8 \\
Dementia & 3 \\
Schizophrenia & 41 \\
Depression & 24 \\
Bipolar disorder & 2 \\
Self-harm & 3 \\
Substance misuse & 4 \\
Malaria & 1 \\
Domestic violence & 1 \\
Sexual abuse & 1 \\
Epilepsy & 5 \\
Intellectual disability & 1 \\
Other & 3 \\
Total & 142 \\
\hline
\end{tabular}

environment is now slowing their development. There is a need to modernise the Mental Treatment Act, to invest more in the recruitment, retention and training of medical staff and to extend mental healthcare beyond cities and urban areas to the villages, where most people live, and to integrate mental health into primary care.

\section{Acknowledgements}

We are grateful to: Dr Michelle Funk and Dr Adukrow of the World Health Organization, and Mr William Same, Director of Mental Health Services, Solomon Islands, for their unfailing support during the placement; Dr D. Oyebode, of the Royal College Psychiatrists, for facilitating the placement; and last but not least Lynne Schofield, for secretarial assistance.

\section{References}

Blignault, I., Bunde-Birouste, A., Ritchie, J., et al (2009) Community perception of mental health needs: a qualitative study in the Solomon Islands. International Journal of Mental Health Systems, 3, 1-17.

Finau, S. \& Losalo, P. (1985) Suicide and parasuicide in Paradise. New Zealand Family Medicine, 9, 27-57.

International Monetary Fund (2009) The Solomon Islands. IMF.

Singh, A. N. (2010) Report on Volunteer Placement in the Solomon Islands with the WHO Pacific Mental Health Network. Royal College of Psychiatrists. Available at http://www.rcpsych.ac.uk/members/ internationalaffairsunit/volunteersprogramme/solomonislandsreport. aspx (accessed March 2011).

Solomon Islands Ministry of Health (2006) Institutional Strengthening Project - Solomon Islands National Health Review. SIMOH.

World Health Organization (2005) 2005 WHO Mental Health Atlas. WHO. 